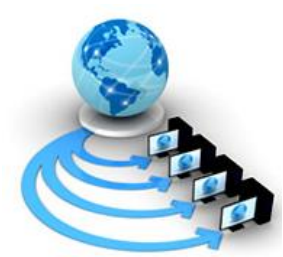

Volume 10, No. 3, May-June 2019

\title{
MINIATURIZED MICROSTRIP DUAL PATCH ANTENNA FOR 2.4 GHz WIFI APPLICATIONS
}

\author{
Yasser Mohammad Al-Sharo \\ Faculty of Information Technology, Ajloun National University \\ Ajloun, 26810, Jordan
}

\begin{abstract}
The implications of the WiFi technology are rapidly expanded due to the revolution of this technology in the telecommunication domain. The coverage space of the Wi-Fi sources still an issue, which limit the usability of the WiFi in various applications such as home, offices, hotels, and restaurants. The patch antenna is effective technology that can strength the signals gaining and distribution of the WiFi. This study proposes patch antenna design for the indoor WiFi applications of $2.4 \mathrm{GHz}$. The main objective of this study is to present miniaturized patch antenna of effective Omni-directional radiation based on the $2.4 \mathrm{GHz}$ frequency. The proposed patch antenna is structured as dual rectangle shapes like the eye glass shape. The size of the antenna substrate is $15 \mathrm{~mm} * 25 \mathrm{~mm} * 1.4 \mathrm{~mm}$ in order to ensure the miniaturized properties of the antenna. The bottom side of the substrate is printed with a microstrip feed line, and the copper is the material of the antenna. The proposed patch antenna is applied on S11 parameters that support the WiFi applications of 8.2.11g standard. The operating frequency is 2.4 $\mathrm{GHz}$ with $50 \Omega$ as input impedance. The gain mode is about $1.8 \mathrm{~dB}$ that constrained by return loss less than $-10 \mathrm{~dB}$. To evaluate the proposed antenna, the Vector Network Analyzer is applied using tool called CST Studio Suite. The simulation shows that the proposed antenna address the Omni-directional radiation of $2.4 \mathrm{GHz}$ frequency under gaining loss less than $-10 \mathrm{Db}$. The efficiency of the antenna radiation records about $72 \%$, which is good records comparing with the past studies. The main contribution of this study is the effectiveness of the miniaturized properties of the proposes patch antenna.
\end{abstract}

Keywords: Patch antenna; Miniaturized; Radiation; Omni-directional; $2.4 \mathrm{GHz} \mathrm{WiFi}$;

\section{INTRODUCTION}

The development in the telecommunication industry is expanded in the last two decades (Kruger et al., 2015; Gu et al., 2015). The WiFi technology is important telecommunication domain due to its portability features. The portable WiFi devices allow the accessing of the internet services in anytime and from anywhere (Sarkar et al., 2016). There are wide applications of the wireless internet connection using WiFi such as GPS, satellites, in hotels, in home, and in restaurants (Akila et al., 2018). According to Torres-Sospedra et al. (2016), The WiFi is telecommunication technology that can gain and radiate the frequency in the domain range between 2.4-5 GHz. The transfer rate of the $\mathrm{WiFi}$ is upt to $54 \mathrm{Mbps}$, and the radiation coverage space is up t0 200 meters. The WiFi is able to transfer services of any data such as video, audio, and text (Lee et al., 2007).

One of the most important challenges that faced by the WiFi is the coverage space and Omni-directional radiation (Hasan et al. 2017; Akila et al., 2018). The limit if the coverage space of the WiFi is 50 to 200 meters, which limit the implications of this technology. On the other hand, the WiFi technology face challenge in radiate the frequencies in Omni-directional like vertical and horizontal directivities (Chen et al., 2017). These two challenges present the importance of the antenna technology to strength the frequency radiation by $\mathrm{WiFi}$ devices. The Antenna is an electrical jointer that connected with the source of the signal in order to strength the signal distribution for the destination devices (Akila et al., 2018).
Weng et al. (2015) mentioned that the antenna technology was investigated by researchers since the early 1990s in order to improve the coverage space of the radio frequency. There are many factors effects on the antenna effectiveness such as the antennas shapes and sizes (Singh \& Tripathi, 2011). For WiFi applications, The patch antenna is most suitable antennas due to its miniaturized properties (Akila et al., 2018). The dimension sizes of the patch antenna are usually designed in millimeters, and the most effective shape is the rectangular (Sharma \& Hashmi, 2014; Hasan et al. 2017). The miniaturized properties of the patch anntenas are deal with the portability characteristics of the $\mathrm{WiFi}$ devices. On the other hand, the rectangular shape of the patch antenna provides efficient Omni-directional radiation.

Basically, the structure of the patch antenna composed of three main elements namely; substrates, ground, and patch (Sharma et al., 2011). The substrate represents the edges of the antenna, while the ground the bottom side if the antenna. The patch is the core element of the antenna and it is usually made of conducting material such as copper. The patch gain the signals through feed line called microstrip that etched on the dielectric substrate. Then, the patch radiates the signals for the destination devices in the coverage space of $\mathrm{WiFi}$. The sizes of patch antenna dimensions are represented by Width $(\mathrm{W}) *$ Length $(\mathrm{L}) *$ thickness. Figure 1 illustrates the general structure of the patch antenna. 


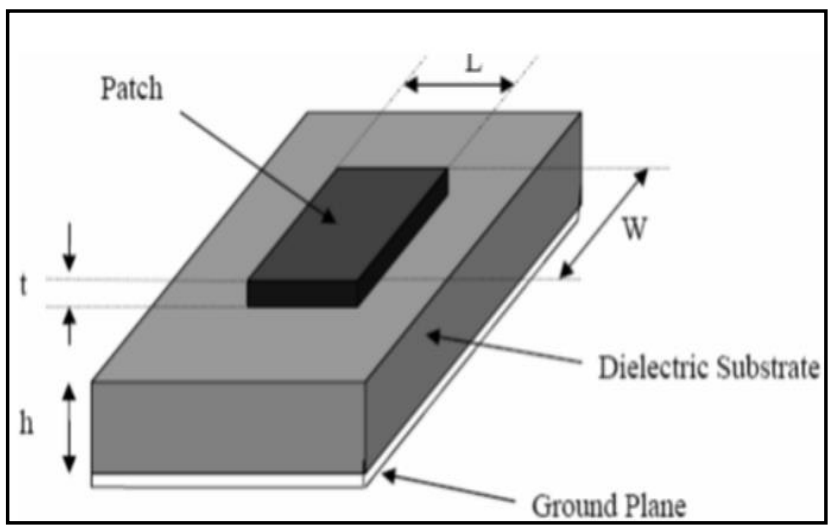

Figure 1: General structure of patch antenna (Sharma et al., 2011)

The Microstrip patch antenna is fed with many methods but the most common methods are the coaxial probe, aperture coupling and proximity coupling (Sharma et al., 2011). What happens in the contacting method is that the RF power is fed directly to the radiating patch and in the non contacting method is that the electromagnetic field coupling is done to transfer power between the radiating patch and microstrip line. The most important thing to take note of is the maximum transfer of power that is to say the feed line should match with the input impedance of the antenna. Figure 2 illustrates the microstrip line in the patch antenna.

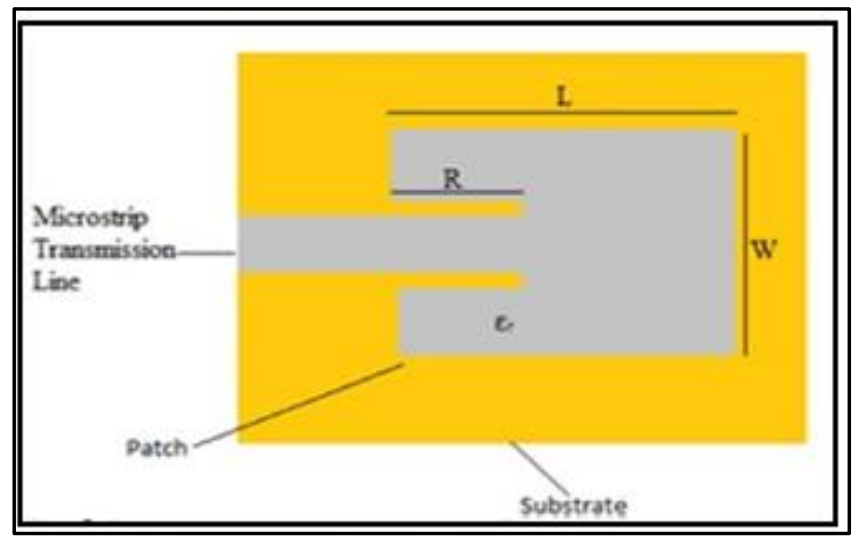

Figure 2: Microstrip patch antenna (Sharma et al., 2011)

The patch antenna is work based on S11 parameters, which represent the input-output relationship between the communications ports (Sivia \& Bhatia, 2015). Simply put, S11 antenna means that there are one direct connection port between the source device and the antenna, and there are one direct connection port between the antenna and the destination devices.

Based on the above discussion, the main aim of this study is to design miniaturized patch antenna for $\mathrm{WiFi}$ applications of $2.4 \mathrm{GHz}$ frequency. The proposed design would provide efficient Omni-directional radiation under the configuration of S11 parameters. The next section presents related works on the patch antenna for $\mathrm{WiFi}$ applications, section 3 explain the research methodology, section 4 discusses the results, and section 5 provide the conclusion and the future works.

\section{RELATED WORKS}

The shapes of the patch antenna can be designed as circular, square, rectangular, and triangular. However, the rectangular antenna is the most suitable shape due to effectiveness of frequency radiation based on the rectangular vectors (Sidhu et al., 2015; Shumba, 2017). In the antenna of rectangular shape, it is important to address the miniaturized properties of the antenna size. According to Garg (2001), the design of the patch antenna can be performed based on three dimensions; (1) the "dielectric constant of the substrate" (Er), the frequency of operation (fr), and the height of the dielectric substrate (h). Based on these three dimensions, the antenna Width (w) can be decided using the following Equation 1 (Garg, 2001; Sidhu et al., 2015; Shumba, 2017):

$$
W=\frac{\mathrm{c}}{2 f_{r}} \frac{1}{\sqrt{\frac{\varepsilon_{r}+1}{2}}}
$$

where $\mathrm{c}$ is the light free space velocity

On the other hand, the effective length (Leff) of the antenna can be calculated based on the following equation 2 (Garg, 2001; Sidhuet al., 2015; Shumba, 2017):

$$
L_{e f f}=\frac{c}{2 f_{r} \sqrt{\varepsilon_{r e f f}}}-2 \Delta L
$$

Where Eff is the effective dielectric constant and $\Delta \mathrm{L}$ is the possible length extension. Eff and $\Delta \mathrm{L}$ can be calculated using the following formulas (Garg, 2001; Sidhuet al., 2015; Shumba, 2017):

$$
\begin{gathered}
E_{f f}=\frac{\varepsilon_{r}+1}{2}+\frac{\varepsilon_{r}-1}{2}\left(\frac{1}{\sqrt{1+\frac{12 h}{w}}}\right) \\
\Delta \mathrm{L}=0.412 \mathrm{~h} \frac{\left(\varepsilon_{r+0.3}\right)\left(\frac{w}{h}+0.264\right)}{\left(\varepsilon_{r}-0.258\right)\left(\frac{w}{h}+0.8\right)}
\end{gathered}
$$

Based on equation 3 and 4, the actual length (L) of the patch antenna can be calculated using the following formula 5 (Garg, 2001; Sidhuet al., 2015; Shumba, 2017):

$$
\mathrm{L}=\mathrm{Leff}-2 \Delta \mathrm{L}
$$

The above five equations are helpful to design the dimensions sizes of the patch antenna $\mathrm{W} * \mathrm{~L} * \mathrm{~T}$. Another important issue in the antenna design is the microstrip line feed, which is linked to the patch and the microstrip feed have smaller width comparing with the width of the patch and this feed arrangement has the advantage that the feed can be etched on the same substrate to provide a planar structure (Li \&Luk, 2016). The inset cut in the patch done to match the impedance of the microstrip feed lines to the patch without the use any additional matching element. All of this is done by properly controlling the inset position. Therefore this is an easy feeding technique is easier in modeling and as impedance matching (Shumba, 2017). Figure 3 shows the insertion techniques of microstrip line feed. The coaxial probe technique of microstrip fed is suitable due to internal insertion, whereby the microstrip protected in the antenna itself (Shumba, 2017). 


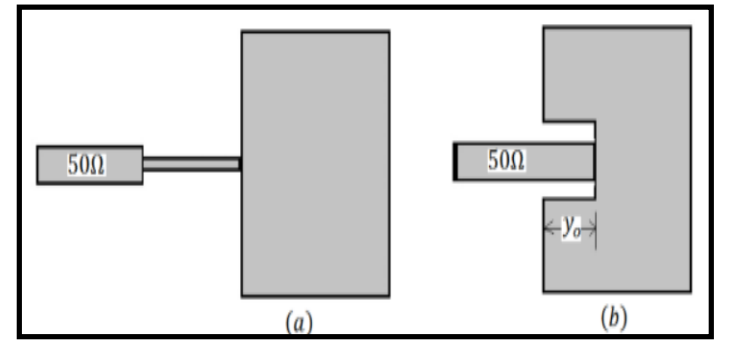

Figure 3: Insertion techniques of microstrip line feed (Singh

\& Tripathi, 2011)

There are many works were conducted on the patch antenna for WiFi applications. All of the related works focus on the miniaturized features of the antenna design, and the Onmidirectional raditation of the designed antenna. Sharma and Hashmi (2014) proposed rectangular patch antenna of size $80 * 78.93 * 1.7 \mathrm{~mm}$. The simulation results using HFSS tool show that the of the study show that the proposed antenna records $2.52 \mathrm{dBi}$ as gain effectiveness at the $2.4 \mathrm{GHz} \mathrm{WiFi}$ applications. Although the study record good results of antenna gain, the radiation efficiency was not tested. Another study is conducted by Weng et al. (2015), and this study proposed miniaturized patch antenna for the WiFi applications of $2.35-2.45 \mathrm{GHz}$. The designed antenna is rectangular of size $50 * 50 * 1.6 \mathrm{~mm}$. The testing of Weng et al. (2015) antenna present axial ratio more than $15 \mathrm{Db}$, which is considered as linear polarized. The results show that the obtained bandwidth is over $1100 \mathrm{MH}$, which is wider than that required bandwidth $(100 \mathrm{MHz})$, the researchers try to justify the non-logical results, but the results still weak due to high recoded bandwidth.

Afridi (2015) proposed patch antenna for WiFi applications of $2.4 \mathrm{GHz}$ frequency. The shape of the proposed patch antenna is traditional rectangular. The dimensions size of the proposed are: the patch size is $38 * 38 \mathrm{~mm}$; the thickness of the substrate is $3 \mathrm{~mm}$; the ground size is $56 * 56 \mathrm{~mm}$. The microstrip patch antenna is based on coaxial probe feeding method, and the microstrip tall is $6 \mathrm{~mm}$. Afridi (2015) focuses on test the frequency gain of the WiFi applications. Based on the simulation experimental results, the proposed patch antenna records Omni-directional gain, and the maximum gain of the antenna is $8.27 \mathrm{~dB}$. Babu and Menon (2016) suggested Open loop resonator filter antenna to filter the input signals and reduce the gain loss of the patch antenna. The proposed filter is recommended to patch antenna of rectangular shape for $\mathrm{WiFi}$ applications. The formula analysis of the suggested open loop resonator filter antenna shows that the filtering processes would decrease the gain loss of the patch antennas. The study just discusses the patch antenna in general without any details like the sizes.

Hasan et al. (2017) proposes patch antenna of multi rectangular shapes. The antenna size is $30 * 20 * 0.08 \mathrm{~mm}$. The antenna was tested based on WiFi and WiMAX standards using tool called "CST Microwave studio". The simulation results show that the radiation efficiency is about $80 \%$ under gaining loss of less than $-10 \mathrm{~dB}$. The main lack of this study is that the gain was not clarified in clear way. Djafri et al. (2017) propose microstrip Y shape in order to enhance the gain effectiveness of patch antenna of size 13 $\mathrm{mm} * 8.9 \mathrm{~mm} * 1.6 \mathrm{~mm}$. The antenna is designed for WiFi applications of $2.5 \mathrm{GHz}$. The CST simulation shows that the proposed microstrip shape could enhance the gaining loos of the patch antenna. However, the radiation efficiency is not tested.

Akila et al. (2018) designed rectangular patch antenna for WiFi applications of $2.4 \mathrm{GHz}$ frequency. The researchers focus on strength the antenna gain and radiation through the Alumina material of the antenna substrate. The dimensions sizes of the proposed antenna are: $26.89 \mathrm{~mm}$ as patch width; $19.781 \mathrm{~mm}$ as patch length; the ground width is $35 \mathrm{~mm}$; the ground length is $28 \mathrm{~mm}$; the substrate thickness is $1.5 \mathrm{~mm}$. The microstrip of tall $21.06 \mathrm{~mm}$ is attached in the proposed patch antenna. Based on the proposed patch antenna of Akila et al. (2018), the gain effectiveness is $4.79 \mathrm{~dB}$ of Omni-directional pattern. However, the radiation efficiency is not tested in the study of Akila et al. (2018).

Table 1 summarizes the conducted works on the patch antenna for WiFi applications. Most of works are focuses on the miniaturized factor of the patch antenna. Most of the designed antennas are take the rectangular shape. Some of the studies obtain the gaining tests, while other studies obtain the radiation test. Hence, the testing of the Omnidirectional gaining and radiation should conducted in this study to fill the research gap.

Table 1: Related works of Patch antenna

\begin{tabular}{|c|c|c|c|c|}
\hline $\begin{array}{c}\text { Researche } \\
\mathbf{r}\end{array}$ & $\begin{array}{c}\text { Miniaturize } \\
\text { d Factor }\end{array}$ & $\begin{array}{c}\text { Antenna } \\
\text { Shape }\end{array}$ & $\begin{array}{c}\text { Test } \\
\text { Gai } \\
\text { n }\end{array}$ & $\begin{array}{c}\text { Test } \\
\text { Radiatio } \\
\text { n }\end{array}$ \\
\hline $\begin{array}{l}\text { Sharma } \\
\text { and } \\
\text { Hashmi } \\
\text { (2014) }\end{array}$ & $\checkmark$ & $\begin{array}{c}\text { Rectangul } \\
\text { ar }\end{array}$ & & X \\
\hline $\begin{array}{l}\text { Weng et } \\
\text { al. (2015) }\end{array}$ & $\checkmark$ & $\begin{array}{c}\text { Rectangul } \\
\text { ar }\end{array}$ & & $X$ \\
\hline $\begin{array}{l}\text { Afridi } \\
(2015)\end{array}$ & $\checkmark$ & $\begin{array}{l}\text { Rectangul } \\
\text { ar }\end{array}$ & & $\mathrm{X}$ \\
\hline $\begin{array}{l}\text { Saraswat } \\
\text { and Kumar } \\
(2016)\end{array}$ & $\checkmark$ & Circular & $\mathrm{X}$ & $\checkmark$ \\
\hline $\begin{array}{l}\text { Babu and } \\
\text { Menon } \\
(2016)\end{array}$ & $\mathrm{X}$ & $X$ & & $X$ \\
\hline $\begin{array}{l}\text { Hasan et } \\
\text { al. (2017) }\end{array}$ & $\checkmark$ & $\begin{array}{c}\text { Rectangul } \\
\text { ar }\end{array}$ & $\mathrm{X}$ & $\checkmark$ \\
\hline $\begin{array}{l}\text { Djafri et } \\
\text { al. }(2017)\end{array}$ & $\checkmark$ & $\begin{array}{l}\text { Rectangul } \\
\text { ar }\end{array}$ & & $\mathrm{X}$ \\
\hline $\begin{array}{l}\text { Akila et al } \\
(2018)\end{array}$ & $\checkmark$ & $\begin{array}{l}\text { Rectangul } \\
\text { ar }\end{array}$ & & $X$ \\
\hline
\end{tabular}

III. RESEARCH METHODOLOGY

Figure 4 illustrates the research methodology phases, which consists of three main phases. The first phase is the design of the patch antenna through design the patch shape, material of the antenna, and the sizes of the antenna elements. The second phase is the simulation using CST studio tool, and through this tool the antenna simulation can 
be developed, and the simulation environment can be identified such as the measurement frequency $(2.4 \mathrm{GHz})$ and S11 parameters. The third phase is the antenna evaluation based on the gaining loss, the radiation efficiency and the Omni-directional pattern.

\section{Stage 1: Patch Antenna Design}

Dimensions of antenna substrate, patch, and ground.

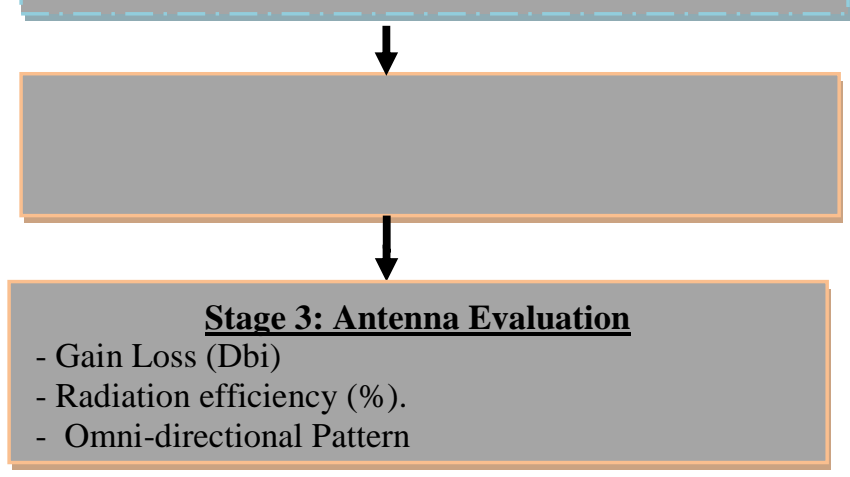

Figure 4: Design of Research Methodology

First of all the antenna shape is designed as dual rectangular shape due to effectiveness of this shap in gain and radiated the frequencies in Omni-directional patter. The material of the antenna is the copper due to quality of this material in protect the transmitted signals. Based on the equations that explained in section 2, the Width size (W) of the proposed antenna is $15 \mathrm{~mm}$, the Length size (L) is $25 \mathrm{~mm}$, and the he thickness is $1.4 \mathrm{~mm}$. hence the miniaturized size of the proposed antenna is $15 * 25 * 1.4 \mathrm{~mm} 3$, which is smaller than the provided antennas in several studies in this domain like Sharma and Hashmi (2014), Weng et al. (2015), and Hasan et al. (2017). Figure 5 presents the proposed antenna design in this study.

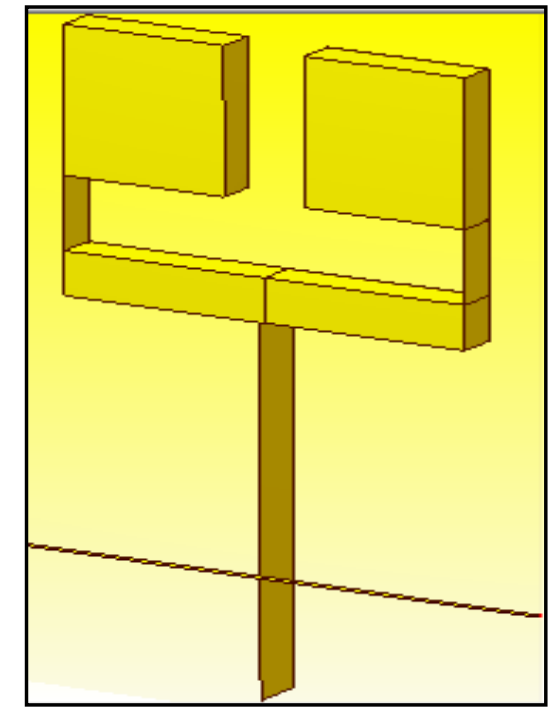

Figure 4: Proposed Patch Antenna Design

Based on the above Figure 4, the antenna patch is dual rectangular shape of $6 * 5 * 1.4 \mathrm{~mm} 3$. The patch is connected with arms of $0.5^{*} 3 \mathrm{~mm} * 0.9 \mathrm{~mm}$ and basis of $6 \mathrm{~mm} * 2 \mathrm{~mm}$ $* 0.9 \mathrm{~mm}$. The arms and basis is smaller than the patch in order to increase the gaining effectiveness of the signals that received from the microstrip line. The microstrip fed line is attached with the patch basis, and it is allocated inside the antenna substrate; the tall of the microstrip line is $9 \mathrm{~mm} *$ $0.9 \mathrm{~mm}$. The size of antenna ground is $15 \mathrm{~mm} * 4 \mathrm{~mm}$. it is necessary to mention that all sizes of antenna elements are tested based on the S11 parameters of the study environment (2.4 GHz frequency). Using the CST tool, the proposed antenna is tested on the WiFi of $2.4 \mathrm{GHz}$ standard and $\mathrm{S} 11$ parameters. Table 2 presents the simulation environment of the proposed antenna.

Table 2: Simulation environment

\begin{tabular}{|l|l|}
\hline Feature & Attribute \\
\hline Antenna Shape & Dual rectangular \\
\hline Antenna Material & Copper \\
\hline Miniaturized & $15^{*} 25^{*} 1.4 \mathrm{~mm} 3$ \\
\hline WiFi frequnacy & $\begin{array}{l}2.4 \mathrm{GHz}(2.0-3.0) \quad \mathrm{GHz} \\
\text { incremented by } 4 \mathrm{MHz}\end{array}$ \\
\hline Power Impedance & $50 \Omega$ \\
\hline Gain vector & $-180 \mathrm{o}<=0<=180 \mathrm{o}$ \\
\hline Gaining loss $(\mathrm{dB})$ & Less than $-10 \mathrm{~dB}$ \\
\hline Radiation efficiency & $\%$ \\
\hline Radiation Pattern & Vertical and horizontal \\
\hline
\end{tabular}

\section{RESULTS DISCUSSION}

Based on the simulation test using CST tool, there are many evaluations are conducted to measure the performance of the proposed patch antenna for WiFi application of $2.4 \mathrm{GHz}$. The most important evaluations are the gaining loss based on S11 parameters, the radiation patterns of the proposed antenna, and the radiation efficiency of the proposed antenna. Figure 5 illustrates the gaining loss based on the $\mathrm{S} 11$ mode. The gain mode of the proposed antenna is about $1.8 \mathrm{~dB}$ that constrained by return loss less than $-10 \mathrm{~dB}$ (about $-21 \mathrm{~dB}$ at $2.4 \mathrm{GHz}$ ). In other words, the proposed 
antenna design could gain effective transmission from the internet source at $2.4 \mathrm{GHz}$.

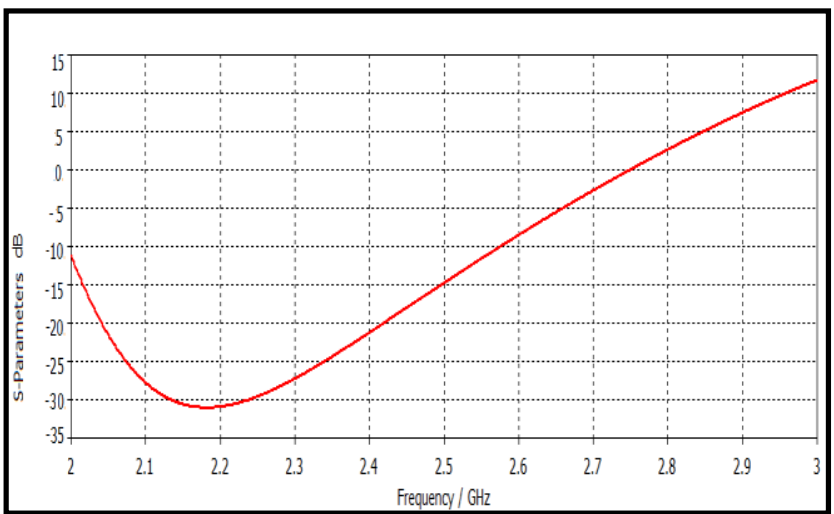

Figure 5: Gaining Measurement of the proposed antenna

Depend on the proposed antenna design, the pattern of the radiation is tested at $2.4 \mathrm{GHz}$. Take in account that the Omni-directional pattern is one of the important purposes of this study. Figure 6 illustrates the radiation pattern of the proposed antenna design. The test of radiation pattern shows that the proposed antenna design provides effective Omnidirectional radiation at $2.4 \mathrm{GHz}$ frequency. This indicates that the proposed antenna could radiate the gained data for the destination devices in various directions i.e. vertically and horizontally.

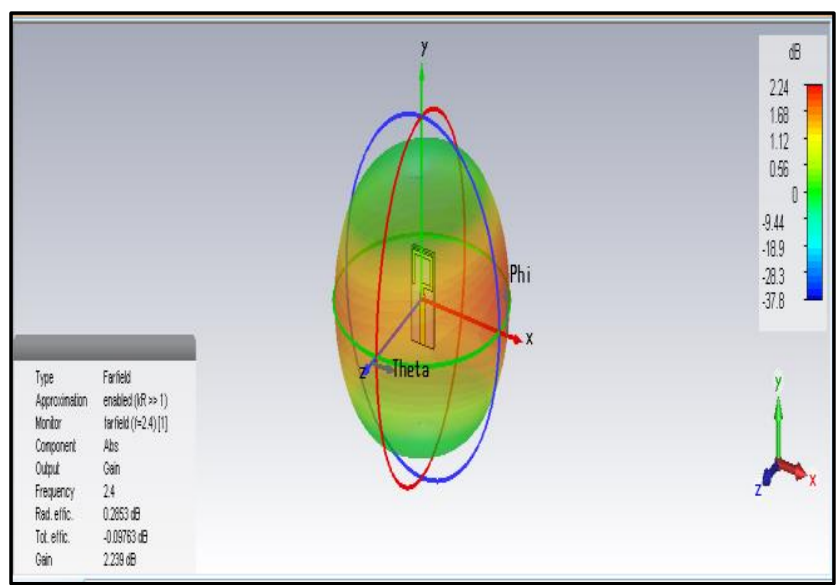

Figure 6: Radiation Pattern of the proposed antenna

In order to confirm the evaluation of the proposed antenna directivity, the Fairfield of left and right directivity is conducted. Figure 7 present the Fairfield directivity of the proposed antenna. It is clear that the proposed antenna can radiate the data at $2.4 \mathrm{GHz}$ in various direction such as left and right polarization. This means that the proposed antenna could provide omni-directional radiation in various angles ($180<=\omega<=180$ ). The $\mathrm{E}$ and $\mathrm{H}$ fields are in the normal range in the omni-directional radiation at $2.4 \mathrm{GHz}$ frequency. Hence, the design of the proposed miniaturized antenna provides effective results in the evaluation of the gaining and radiation pattern tests. Based on these results, it is necessary to evaluate the radiation patterns of the proposed antenna.
Farfed Directivey Abs (Phin=9on)

Farfeld Directivity Left Polarisation (Phi=90)

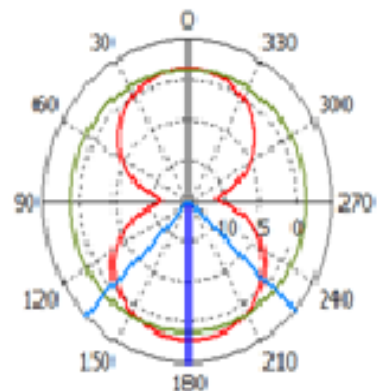

Theta / Degree ws: dil

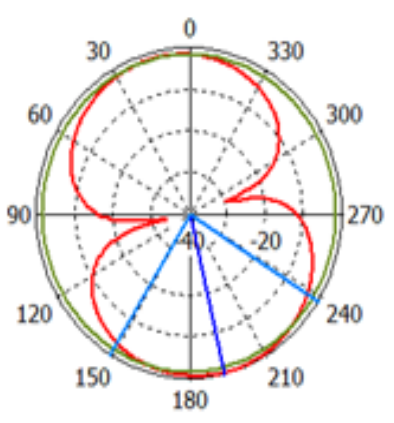

Theta / Degree vs. dBi
Figure 7: Fairfield directivity of the proposed antenna

Figure 8 illustrates the radiation efficiency of the proposed antenna based on the WiFi environment of $2.4 \mathrm{GHz}$. The total efficiency of the radiation is about $72 \%$ are the frequency $2.4 \mathrm{GHz}$. In other meaning, the proposed antenna is effective in gain the data and radiates it through strong signals via the $2.4 \mathrm{GHz}$ frequency. The radiation efficiency of the proposed antenna is very good comparing with other studies such as Hasan et al. (2017), Saraswat and Kumar (2016), and Weng et al. (2015).

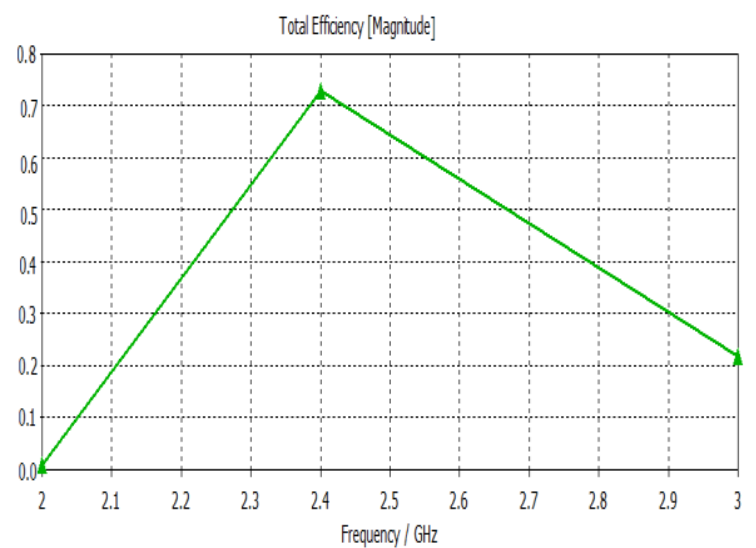

Figure 8: Radiation Efficiency (\%)

\section{CONCLUSION AND FUTURE WORKS}

This study propose dual rectangular miniaturized patch antenna of size $15 * 25 * 1.4 \mathrm{~mm}^{3}$. The design of the antenna is conducted based on the recommended features in the domain of patch antennas for WiFi applications. The simulation results using CST tool show that the proposed antenna is effective in gain the signals $(<-10 \mathrm{~dB})$ at 2.4 $\mathrm{GHz}$, radiate the signals in Omni-directional patters, and efficient in radiate most gained signals $(72 \%)$ at $2.4 \mathrm{GHz}$. Therefore, the proposed patch antenna could helpful in enhance the coverage space of the WiFi applications at 2.4 GHz. The main contribution of this study is the miniaturized properties of the proposed patch antenna comparing with the previous works in this domain. In the future, the real fabrication would be developed for real testing of the proposed patch antenna. 


\section{REFERENCES}

[1] Afridi, M. A. (2015). Microstrip patch antennadesigning at $2.4 \mathrm{GHz}$ frequency. Biological and chemical research, 2015, 128-132.

[2] Akila, P., Akshaya, P., Aparna, L., \& Mol, J. M. S. (2018). DESIGN AND ANALYSIS OF MICROSTRIP PATCH ANTENNA USING ALUMINA AND PAPER SUBSTRATE FOR WIFI APPLICATION.

[3] Babu, N. C., \& Menon, S. K. (2016, February). Design of a Open loop resonator based filter Antenna for WiFi applications. In Signal Processing and Integrated Networks (SPIN), 2016 3rd International Conference on (pp. 236-239). IEEE

[4] Chen, C., Chen, Y., Han, Y., Lai, H. Q., Zhang, F., \& Liu, K. R. (2017). Achieving centimeter-accuracy indoor localization on WiFi platforms: A multi-antenna approach. IEEE Internet of Things Journal, 4(1), 122134.

[5] Djafri, K., Challal, M., Dehmas, M., Mouhouche, F., Aksas, R., \& Romeu, J. (2017, October). A novel miniaturzed dual-band microstrip antenna for WiFi/WiMAX applications. In Electrical EngineeringBoumerdes (ICEE-B), 2017 5th International Conference on (pp. 1-5). IEEE

[6] Garg, R. (2001). Progress in Microstrip antennas. IETE Technical Review, 18(2-3), 85-98.

[7] Gu, Y., Saad, W., Bennis, M., Debbah, M., \& Han, Z. (2015). Matching theory for future wireless networks: fundamentals and applications. IEEE Communications Magazine, 53(5), 52-59.

[8] Hasan, C. Z. U., Khan, A. A., Fahim-Al-Fattah, M., Amin, M. A., \& Mohammad, S. (2017, May). A novel quad-band microstrip patch antenna for WLAN, WiFi, WiMAX applications. In 2017 IEEE 9th International Conference on Communication Software and Networks (ICCSN) (pp. 718-721). IEEE.

[9] Kruger, C. P., Abu-Mahfouz, A. M., \& Hancke, G. P. (2015, March). Rapid prototyping of a wireless sensor network gateway for the internet of things using off-theshelf components. In Industrial Technology (ICIT), 2015 IEEE International Conference on (pp. 19261931). IEEE

[10] Lee, J. S., Su, Y. W., \& Shen, C. C. (2007, November). A comparative study of wireless protocols: Bluetooth, UWB, ZigBee, and Wi-Fi. In Industrial Electronics Society, 2007. IECON 2007. 33rd Annual Conference of the IEEE (pp. 46-51). Ieee.
[11] Li, Y., \& Luk, K. M. (2015). 60-GHz substrate integrated waveguide fed cavity-backed aperturecoupled microstrip patch antenna arrays. IEEE Transactions on Antennas and Propagation, 63(3), 1075-1085.

[12] Saraswat, R. K., \& Kumar, M. (2016). Miniaturized slotted ground UWB antenna loaded with metamaterial for WLAN and WiMAX applications. Progress In Electromagnetics Research, 65, 65-80.

[13] Sarkar, S. K., Basavaraju, T. G., \& Puttamadappa, C. (2016). Ad hoc mobile wireless networks: principles, protocols, and applications. CRC Press.

[14] Sharma, D., \& Hashmi, M. S. (2014, December). A novel design of tri-band patch antenna for GSM/WiFi/WiMAX applications. In Microwave and RF Conference (IMaRC), 2014 IEEE International (pp. 156-158). IEEE.

[15] Sharma, G., Sharma, D., \& Katariya, A. (2011). An Approach To Design And Optimization Of Wlan Patch Antennas For Wi-Fi Applications. International Journal of Wireless Communication, 1(2), 9.

[16] Shumba. P. (2017). Design and characterisation of a microstrip patch antennafor $\mathrm{Wi}-\mathrm{Fi}$. BSc dissertation. Midlands State University, Zimbabwe.

[17] Sidhu, S. K., \& Sivia, J. S. (2015). Comparison of Different Types of Microstrip Patch Antennas. In International Conference on Advancements in Engineering and Technology (ICAET 2015), International Journal of Computer Applications (09758887).

[18] Singh, I., \& Tripathi, V. S. (2011). Micro strip patch antenna and its applications: a survey. Int. J. Comp. Tech. Appl, 2(5), 1595-1599.

[19] Sivia, J. S., \& Bhatia, S. S. (2015, June). Design of fractal based microstrip rectangular patch antenna for multiband applications. In Advance Computing Conference (IACC), 2015 IEEE International (pp. 712715). IEEE.

[20] Torres-Sospedra, J., Montoliu, R., Mendoza-Silva, G. M., Belmonte, O., Rambla, D., \& Huerta, J. (2016). Providing databases for different indoor positioning technologies: Pros and cons of magnetic field and wi-fi based positioning. Mobile Information Systems, 2016.

[21] Weng, Z., Guo, D., Wu, Y., Li, M., Hu, J., Zeng, W., .. \& Zeng, S. (2015, May). A $2.45 \mathrm{GHz}$ microstrip patch antenna evolved for WiFi application. In Evolutionary Computation (CEC), 2015 IEEE Congress on (pp. 1191-1195). IEEE. 